\title{
Changes in choline acetyltranferase distribution in the cervical spinal cord after reversible cervical spinal cord injury
}

\author{
M Nakamura, Y Fujimura, Y Yato, M Watanabe, Y Iwamoto \\ Department of Orthopaedic Surgery, School of Medicine, Keio University, 35 \\ Shinanomachi, Shinjyuku-ku, Tokyo, 160, Japan.
}

\begin{abstract}
Reversible spinal cord injury (SCI) at C6 level in rats, produced by the weight-placed method, resulted in a severe motor functional deficit initially, followed by a gradual recovery. During the recovery, choline acetyltransferase (CAT) distribution in the cervical spinal cord was investigated at 2, 4, 7, 14 and 28 days after the injury by quantitative immunohistochemistry with a fluorescence microphotometry system. At C6 level, the flourescence intensity of the ventrolateral anterior horn $(\mathrm{VLAH})$, which reflected the concentration of CAT, decreased to approximately $50 \%$ of that of the sham-operated group at 2 days. It then recovered to $60 \%$ at 4 days after the injury, and remained unchanged thereafter. Fluorescence intensities in VLAH at C4-5 and C7-8 levels decreased to approximately $60-70 \%$ at 2 days after the injury, but it recovered and increased to $110-130 \%$ thereafter.
\end{abstract}

Keywords: reversible cervical spinal cord injury in rats; choline acetyltransferase; fluorescence microphotometry; quantitative immunohistochemistry.

\section{Introduction}

The introduction of the weight-drop technique by Allen $^{1}$ in 1911 inaugurated the modern era of spinal cord trauma research, and compression injuries have since been studied using the balloon compression technique,$^{2-4}$ the clip compression model, ${ }^{5}$ and the method used in this study, the weightplaced technique. ${ }^{6}$ These techniques all allow the creation of reproducible and graded SCI. Reversible SCI, produced by the placement of a $20 \mathrm{~g}$ weight for $5 \mathrm{~min}$ on the cord, was characterised by an initially severe motor functional deficit followed later by recovery of motor function. However, it remains an unsettled question whether spinal motor neuron function really recovers completely from such a trauma. Choline acetyltransferase (CAT), the final enzyme in acetylcholine synthesis, is known as the most specific marker for cholinergic neurons and its expression sensitively reflects spinal motor neuron function. ${ }^{7}$ In this study, changes in CAT distribution in rat spinal cord after reversible SCI were investigated by quantitating indirect $\mathrm{CAT}$ immunofluorescence of spinal cord sections using a microphotometry system.

\section{Materials and method}

\section{Spinal cord injury model}

Reversible SCI was produced by the modified weight-placed method of Croft et al. ${ }^{6}$ Forty Wistar rats weighing about $250 \mathrm{~g}$ were anaesthetised with pentobarbital $(40 \mathrm{mg} / \mathrm{kg}$, i.p. ) and laminectomy was performed at C5 and C6 under a microscope. The cervical spinal column was stabilised by fixing the skull and a spinous process of T2. In twenty rats, a $20 \mathrm{~g}$ weight was then placed on the exposed dura at C6 level for $5 \mathrm{~min}$ (compression group). In the remaining 20 rats, only laminectomy was performed at C5 and C6 (sham-op group). In another five rats, no operation was performed (non-op group). Rat motor function was then evaluated by the inclined plane method of Rivlin et al ${ }^{8}$ According to the original method, the maximum inclination of the plane at which a rat could maintain itself for $5 \mathrm{~s}$ was recorded, which was used as the rat's motor functional ability. 


\section{Immunohistochemistry}

Four rats each (compression group and sham-op group) were perfused intracardially with $4 \%$ paraformaldehyde in phosphate-buffered saline (PBS, $\mathrm{pH} 7.4$ ) at 2, 4, 7,14 and 28 days after the operation. The spinal cord was then removed and postfixed in the same solution for $2 \mathrm{~h}$ and rinsed in $5 \%$ buffered sucrose at $4{ }^{\circ} \mathrm{C}$ for $12 \mathrm{~h}$. The spinal cord was then divided into three blocks under the microscope: the compressed portion (C6 level); that rostral to it (C4-5 level); and that caudal to it (C7-8 level). Each tissue block was frozen on dry ice and sectioned at $10 \mu \mathrm{m}$ on a cryostat. The sections of non-op group were made by the same procedures above.

The immunohistochemical procedures were performed according to Sutoo's method. ${ }^{9}$ Ten sections from each block were reacted with normal goat serum (Chemicon S-20 (Chemicon Inc, Temecula, CA, USA) diluted 1:20 with PBS) at room temperature for $1 \mathrm{~h}$ and then reacted with anti-CAT rabbit serum (Chemicon AB-143, diluted $1: 100$ with PBS) at $4{ }^{\circ} \mathrm{C}$ for $12 \mathrm{~h}$. After being washed with three changes of PBS for a total $3 \mathrm{~h}$, they were reacted with FITC-labelled, anti-rabbit IgG goat serum (TAGO 4320 (Tago Inc, Burlingame, CA, USA) diluted 1:20 with PBS) at room temperature for $3 \mathrm{~h}$. The stained sections were embedded in $20 \%$ glycerin-PBS.

In the control experiment, the sections of non-op group were processed as above except that the primary antibody, which was made by Bruce, ${ }^{10,11}$ was replaced with normal rat serum.

\section{Analysis of CAT distribution}

CAT immunofluorescence intensity in the spinal cord was measured at several regions using a microphotometry system which was developed by Sutoo et al. ${ }^{12}$

This system consists of a fluorescence microscope, a photomultiplier tube, an auto-scanning stage, and a computer. This system can measure the fluorescence intensity in a small spinal region through a measuring spot. The measuring spot can be selected freely. The spinal section is moved in the X-and Y-directions by means of a high-precision step-motor scanning stage under the objective lens of the fluorescence microscope, and the fluorescence intensity of the entire surface of the section is analysed without the fading of the fluorescence intensity. Fluorescence intensity and its position are transferred to the computer and displayed in two or three dimensions. The background fluorescence intensity can be suppressed with an interference filter which is inserted into the photomultiplier tube.

The microphotometry system was used under the following conditions: excitation range, $420-490 \mathrm{~nm}$; interference filter, $530 \mathrm{~nm}$; photomultiplier voltage, $850 \mathrm{~V}$; objective lens, $20 \times / 0.75$ (magnification/ numerical aperture); and measuring spots, $40 \mu \mathrm{m}$. The fluorescence intensity of uran glass was used as the fluorescence intensity standard, the value of which was $64 .^{12}$

\section{Histopathology}

After the measurement of fluorescence intensities, the slices were stained with hematoxylin-eosin (HE) and luxol fast blue(LFB) for histological examination.

\section{Results}

Evaluation of motor functional deficit

In the sham-op group, there were no motor functional deficits throughout the experiment. In the compression group, motor functional deficits were most prominent at 2 days after the injury (inclined plane angle: $60^{\circ}$ ), when the motor dysfunction was dominant in the upper limbs, but the lower limbs were not so seriously affected and the animals could stand on their lower limbs. Motor function gradually improved after 2 days, and it recovered to almost the same level as that of the sham-op group by the end of the experiment (inclined plane angle: $82.5^{\circ}$ ). Injured animals were able to run normally 3 weeks after injury (Fig 1).

\section{Histopathological findings}

There were no differences histologically between the sham-op group and the non-op group. In the compression group, haemorrhagic lesions were present in the central grey matter at C6 level 2 days after the 


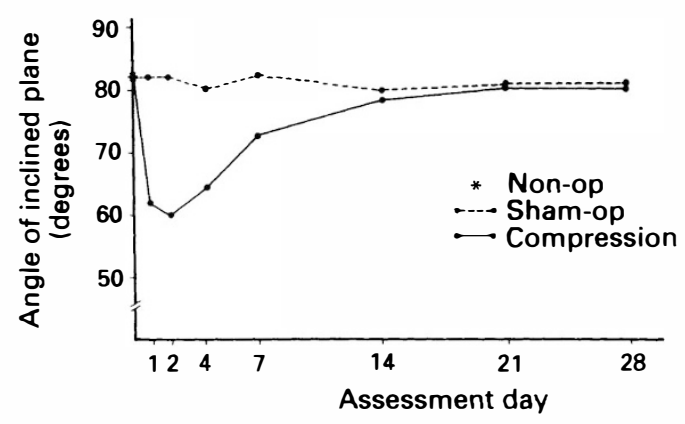

Figure 1 Inclined plane method.

injury (Fig 2a, b). The number of anterior horn cells at C6 level decreased gradually until 4 weeks after injury. According to the decrease, glial cell numbers were increased (Fig 2c, d). No changes in numbers were observed in the anterior horn cells at C4-5 and C7-8 level. The axon and myelin sheaths in the white matter of the spinal cord remained normal except for the posterior column at C6 level (Fig 3a, b).

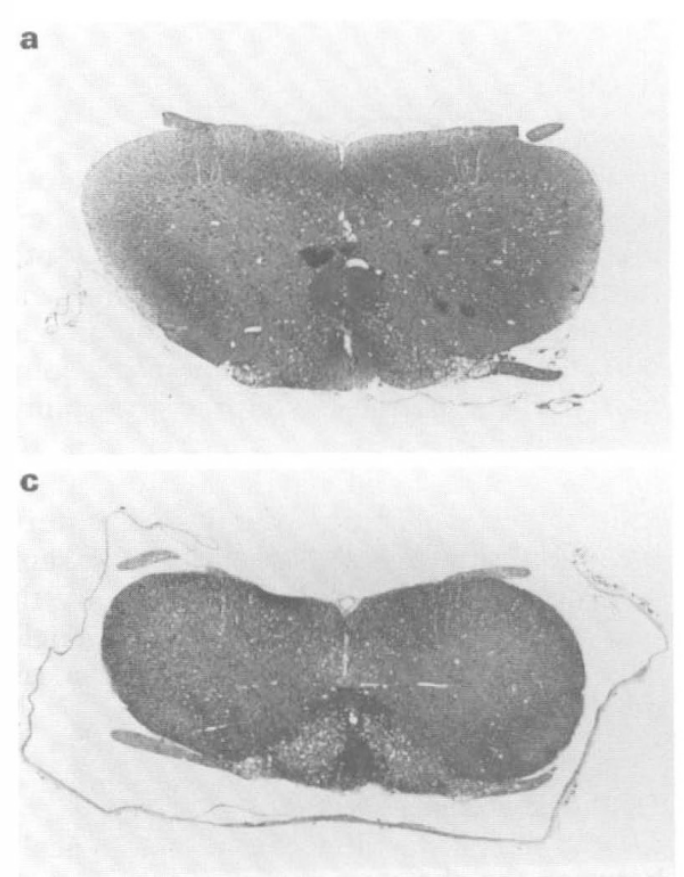

\section{Immunohistochemical findings}

In both the non-op and the sham-op groups, large-sized cells, which appeared to be the motor neurons of the spinal cord, were present in large numbers in the ventrolateral area of the anterior horn (VLAH) (Fig 4). In the control experiment, no CAT immunoreactive neurons were observed in the spinal cord. Fluorescence intensities were uniformly high in VLAH, implying the high concentration of CAT (Fig 5). The spinal cord was divided into seven functional regions (Fig 6) and average values of fluorescence intensity at the measured points were analysed in each region. There was no difference of the average values of VLAH between the non-op group and the sham-op group statistically (Table I). In the sham-op group, time-correlated changes of the average values in the VLAH were not found throughout the experiment (Table II).

In the compression group, CAT immunoreactive neurons at $\mathrm{C} 6$ level were still maintained at 2 days after the injury (Fig 7a), but
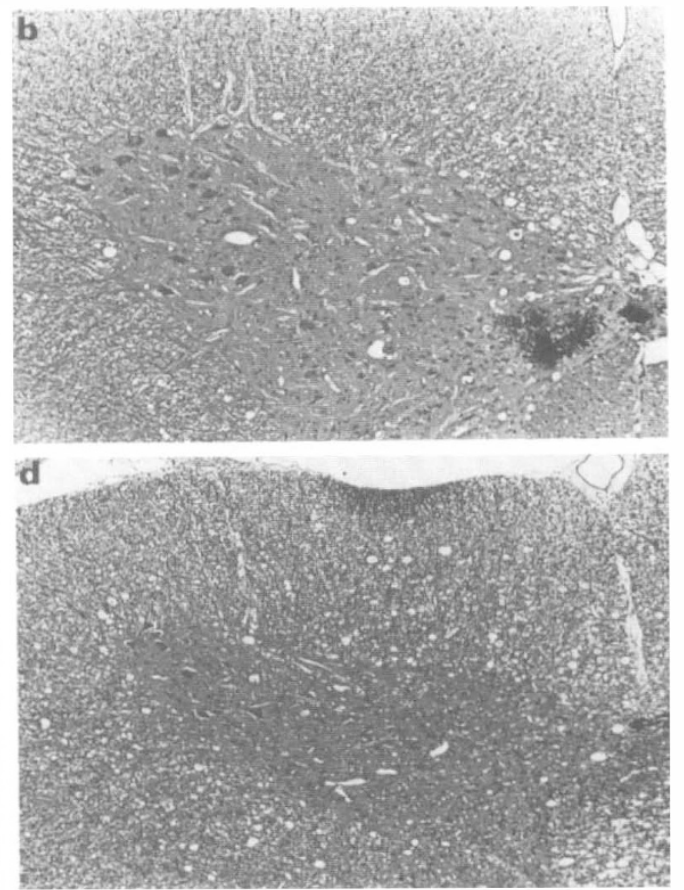

Figure 2 Photomicrograph of the spinal cord at C6 level (the compressed portion). Post injury 2 days (a) $8 \times$, (b) $20 \times$; post injury 4 weeks (c) $8 \times$, (d) $20 \times(\mathrm{HE}+$ LFB staining). 
a

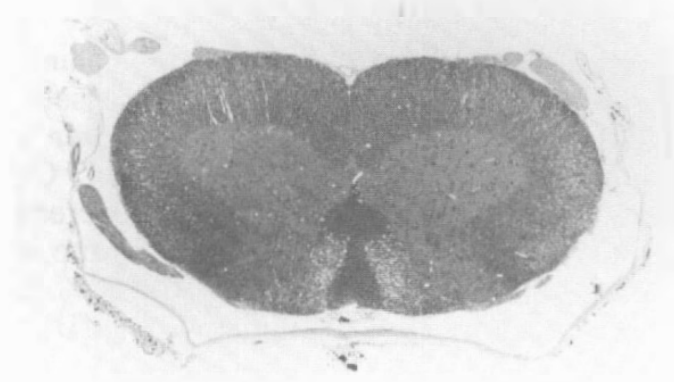

Figure 3 Photomicrograph of the spinal cord at (a) $8 \times)$.

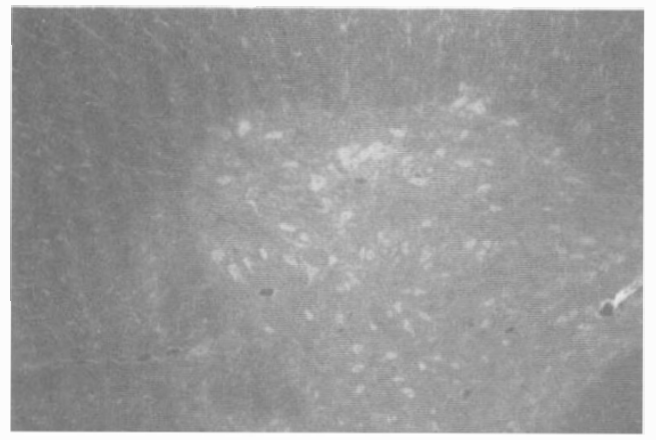

Figure 4 Fluorescence microphotograph of the anterior horn in sham-op group at C6 level (B-excitation, $40 \times$ ).

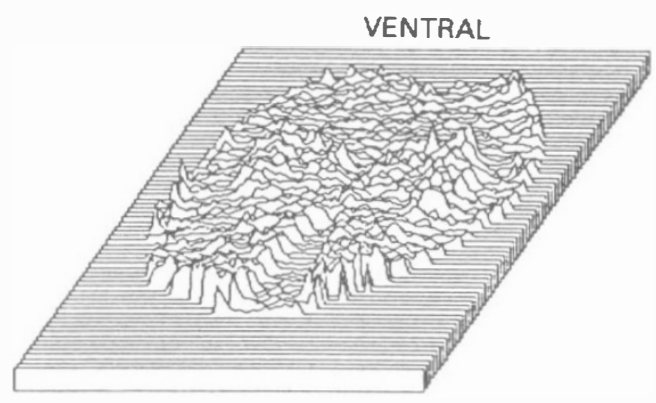

DORSAL

Figure 5 Quantitative distribution of CAT immunofluorescence intensity (three dimensional display).

the number of these decreased gradually until 4 weeks after injury (Fig 7b). On the other hand, both at the $\mathrm{C} 4-5$ and $\mathrm{C} 7-8$ levels, CAT immunoreactive neurons remained normal at 4 weeks following the injury (Fig 8a, b).

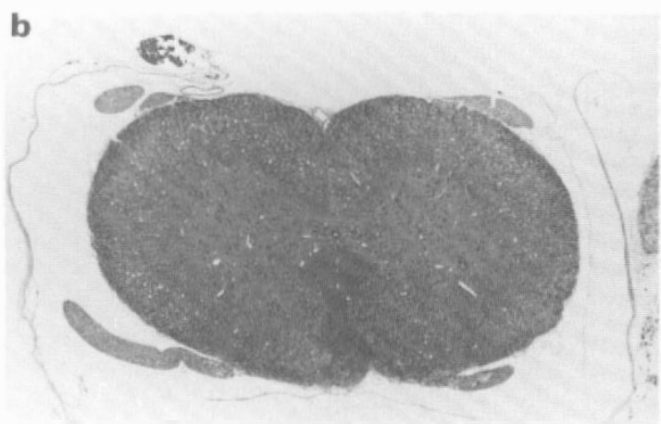

C4-5 level, (b) C7-8 level (HE + LBF staining,

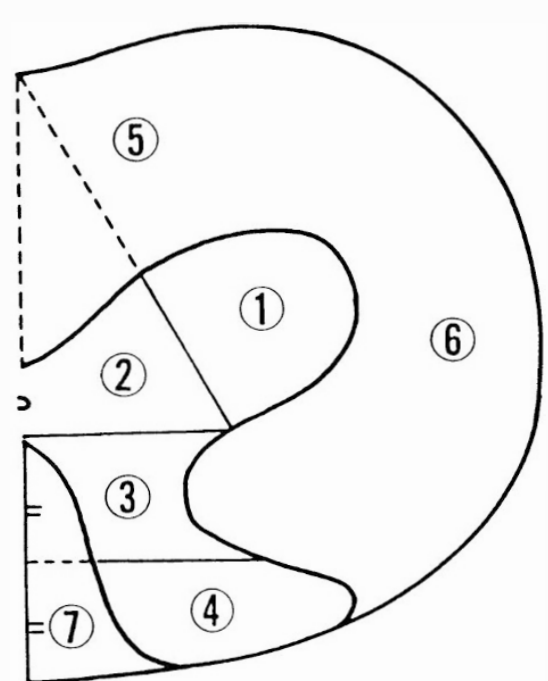

Figure 6 The spinal cord was divided into seven functional regions.

Table I Fluorescence intensity of each region (C6 level)

\begin{tabular}{lcc}
\hline $\begin{array}{l}\text { No. of } \\
\text { region }\end{array}$ & $\begin{array}{c}\text { Non-op group } \\
(n=5)\end{array}$ & $\begin{array}{c}\text { Sham-op group } \\
(n=20)\end{array}$ \\
\hline 1 & $87.6 \pm 1.4$ & $88.2 \pm 1.3$ \\
2 & $69.3 \pm 1.9$ & $66.8 \pm 3.8$ \\
3 & $65.2 \pm 2.5$ & $64.3 \pm 4.2$ \\
4 & $74.2 \pm 2.0$ & $72.9 \pm 2.1$ \\
5 & $34.1 \pm 0.9$ & $33.1 \pm 1.2$ \\
6 & $34.2 \pm 1.6$ & $32.7 \pm 1.1$ \\
7 & $5.4 \pm 0.5$ & $5.3 \pm 0.7$ \\
\hline
\end{tabular}

Each value represents the mean $\pm \mathrm{SE}$ 
Table II Sham-op group: changes of the average values in the ventrolateral anterior horn (VLAH)

\begin{tabular}{lc}
\hline & Fluorescence intensity \\
\hline 2 days post op & $87.9 \pm 1.5(n=4)$ \\
4 days post op & $90.2 \pm 0.7(n=4)$ \\
7 days post op & $88.3 \pm 1.2(n=4)$ \\
14 days post op & $86.9 \pm 2.4(n=4)$ \\
28 days post op & $87.2 \pm 2.2(n=4)$ \\
\hline
\end{tabular}

Each value represents the mean $\pm \mathrm{SE}$

\section{Changes in CAT immunofluorescence} intensity in VLAH after reversible spinal cord injury

At C6 level, CAT immunofluorescence intensities in VLAH decreased to approximately $50 \%$ of those in the sham-op group at 2 days but increased to approximately $60 \%$ at 4 days after the injury. However, no further recovery occurred.

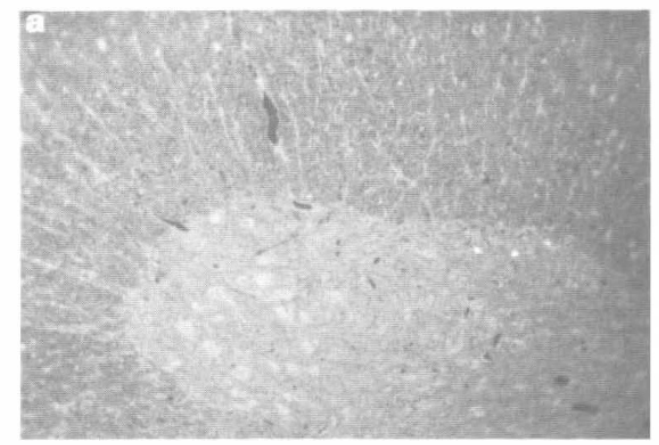

On the other hand, at the C4-5 level, CAT immunofluorescence intensity decreased to $66 \%$ of those of the sham-op group at 2 days, but then increased to $115-120 \%$ at 1 week or more after the injury. Similarly, at the C7-8 level, CAT immunofluorescence intensities decreased to $77 \%$ of those of the sham-op group at 2 days and then increased to $110-130 \%$ at 1 week or more after the injury (Table III).

\section{Discussion}

The fluorescence microphotometry system used in this study is superior to a conventional television image analyser for quantitation. Though it cannot measure the absolute quantity of CAT, it is excellent for the examination of the relative changes of CAT among different groups of animals. ${ }^{9}$

It is interesting and important biochemi-

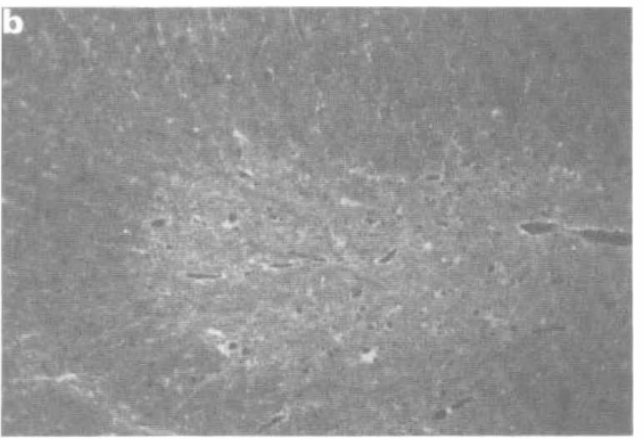

Figure 7 Fluorescence microphotograph of the anterior horn in compression group at C6 level (a) post injury 2 days, (b) post injury 28 days (B-excitation, $40 \times$ ).
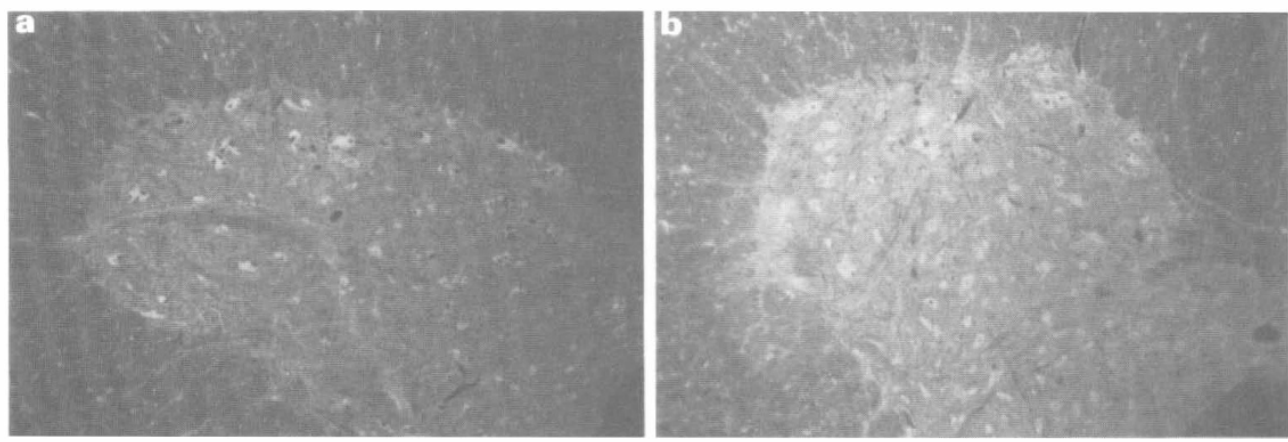

Figure 8 Fluorescence microphotograph of the anterior horn in compression group at 28 days after the injury (a) C4-5 level, (b) C7-8 level (B-excitation, 40×). 
Table III Changes in fluorescence intensities of the VLAH

\begin{tabular}{lrrr} 
& C4-5 level & C6 level & C7-8 level \\
\hline Sham-op group $(n=20)$ & $82.1 \pm 2.2$ & $88.2 \pm 1.3$ & $90.6 \pm 3.8$ \\
Post injury 2 days $(n=4)$ & $54.2 \pm 4.5$ & $46.0 \pm 3.6$ & $70.0 \pm 3.4$ \\
Post injury 4 days $(n=4)$ & $70.7 \pm 4.3$ & $52.0 \pm 3.3$ & $72.3 \pm 7.4$ \\
Post injury 1 week $(n=4)$ & $102.9 \pm 4.7$ & $51.7 \pm 5.1$ & $111.3 \pm 2.7$ \\
Post injury 2 weeks $(n=4)$ & $105.6 \pm 5.2$ & $56.0 \pm 3.6$ & $117.2 \pm 7.9$ \\
Post injury 4 weeks $(n=4)$ & $98.1 \pm 3.4$ & $50.2 \pm 2.7$ & $99.9 \pm 9.3$ \\
\hline
\end{tabular}

Each value represents the mean $\pm \mathrm{SE}$. The fluorescence intensity of uran glass was used as the fluorescence intensity standard, the value of which was 64 measured under the following condition: the excitation range, $420-490 \mathrm{~nm}$; interference filter, $530 \mathrm{~nm}$; photomultiplier voltage, $850 \mathrm{~V}$; objective lens $20 \times / 0.75$ (magnification/numerical aperture); and measuring spot, $40 \mu \mathrm{m} \phi$.

cally that the changes of CAT immunofluorescence intensity in VLAH, reflecting changes of CAT concentration in spinal motor neurons, is correlated to the histopathological and neurological findings in this model. Reversible SCI in the rat results in an initial profound functional deficit, followed by a gradual recovery over a period of a few weeks after the injury. However, this recovery of function has not yet been fully explained. Our findings were that CAT immunofluorescence intensities in VLAH were significantly decreased in parts of the cord distant from the site of trauma at 2 days after the injury, which suggests that some of the functional deficit at this time may reflect low levels of this key enzyme in the synthesis of acetylcholine. Moreover, the persistent low CAT immunofluorescence intensities in VLAH at the site of compression at 4 weeks after the injury suggested that the dysfunction of the motor neurons at the site of compression were irreversible. A strong correlation was found between the late excessive recovery of CAT immunofluorescence intensity in VLAH both rostral and caudal to the injury and the motor functional recovery.

In conclusion, in spite of the fact that irreversible changes occurred at the site of compression, motor function completely recovered, which was due to the recovery and compensatory overexpression of CAT in neighbouring portions of the injured part.

\section{References}

1 Allen AR (1911) Surgery of experimental lesion of spinal cord equivalent to crush injury of fracture dislocation of spinal column. JAMA 57: 878-880.

2 Kobrine AI, Evans DE, Rizzoli H (1978) Correlation of spinal cord blood flow and function in experimental compression. Surg Neurol 10: 54-59.

3 Sandler AN, Tator CH (1976) Effect of acute spinal cord compression injury on regional spinal blood flow in primates. $J$ Neurosurg 45: 660-676.

4 Tarlov IM, Klinger H, Vitale S (1953) Spinal cord compression studies. Experimental techniques to produce acute gradual compression. Arch Neurol Psychiatry 70: 813-819.

5 Rivlin AS, Tator CH (1978) Effect of duration of acute spinal cord compression in a new acute cord injury model in the rat. Surg Neurol 10: 39-43.

6 Croft TJ, Brodkey JS, Nulsen FE (1972) Reversible cord trauma: a model for electrical monitoring of spinal cord function. J Neurosurg 36: 402-406.

7 McCaman RE, MaCaman MW (1976) In: Goldberg AM, Hanin I, editors. Biology of Cholinergic Function. Raven, New York: 485.

8 Rivlin AS, Tator $\mathrm{CH}$ (1977) Objective clinical assessment of motor function after experimental spinal cord injury in the rat. $J$ Neurosurg 47: 577-581.

9 Sutoo D, Akiyama K, Yabe K, Nishida N (1991) Quantitative immunohistochemical distribution of choline acetyltransferase in the rostral forebrain of the rat. Neurosci Res 11: 63-70.

10 Bruce G, Wainer BH, Hersh LB (1985) Immunoaffinity purification of human choline acetyltransferase: comparison of the brain and placental enzymes. J Neurochem 45: 611-620. 
11 Armstrong DM, Bruce G, Hersh LB, Terry RD (1986) Choline acetyltransferase immunoreactivity in neuritic plaques of Alzheimer brain. Neurosci Lett 71: 229-234.

12 Sutoo D, Akiyama K, Maeda I (1988) The development of high sensitivity and high linearity fluorescence microphotometry system for distribution analysis of neurotransmitter in the brain. Folia Pharmacol Jpn 91 : 173-180. 